\title{
Study of Pre Conditional Survey of Existing Building During Tunneling Process
}

\author{
D. Vivek ${ }^{1}$, K. S. Elango ${ }^{2}$, K. Gokul Prasath ${ }^{3}$, V. Ashik Saran ${ }^{4}$, \\ V. B. Ajeeth Divine Chakaravarthy ${ }^{5}$, S. Abimanyu ${ }^{6}$ \\ ${ }^{1,2}$ Assistant Professor, Department of Civil Engineering, KPR Institute of Engineering and Technology, Coimbatore. \\ 2, 3, 4 \&5 Under Graduate Student, Department of Civil Engineering, KPR Institute of Engineering and Technology, Coimbatore.
}

\begin{abstract}
This study develops a systematic approach with detailed step-by-step procedures for safety management of existing buildings adjacent to tunneling excavation. The potential safety risk of a specific nearby building is assessed within four different risk levels, with the spatial neighbor relation and the building health condition taken into account. Corresponding protective measures for buildings at different risk levels are provided according to risk assessment results. A fine balance between the system safety and cost constrains is reached, where the evaluated risk level plays a decisive role in the adoption of numerous simulation analysis tools. Results demonstrate the feasibility of the proposed approach, as well as its application potential. The proposed safety management approach is also worth popularizing in other similar projects, and can be used to increase the likelihood of a successful project in a complex project environment.
\end{abstract}

\section{INTRODUCTION}

Carrying out civil works related to development of infrastructure towards Public Transport System is a challenging task in the present-day urbanization condition. Such Works in City like Bangalore where there is acute shortage of space and Geology controls the progress of construction of metro rail corridor.

Bangalore Metro Rail Corporation Ltd. (BMRCL), taken responsibility for implementing Bangalore Metro Rail Project and faced several difficulties in implementing First Phase of this project. Tunneling in mixed strata, below major roads and old buildings influenced the progress.

Pre conditional survey of the existing buildings near the tunnel line is done for the safety purpose during tunneling process. As a result of the pre conditional survey according to its damage category the building may supported to resist the impact due to tunneling.

\section{TUNNELING PROCESS}

Tunneling by using Tunnel Boring Machines is a very safe tunneling method which has brought drastic improvement in Tunneling works. Earlier machines were of open type wherein shield is used only as a support from soil collapse but face is open. Excavation in this type takes place with help of conventional machines like excavator. Pressure at face of the tunnel cannot be increased in open type machines. In rocky strata, which does not need lining as support, open type machine called Gripper TBM with cutter head is used. Such machines will not have shield. There are two types of Machines in closed shield method, one is Earth pressure balancing machine and the other is slurry machine. Before knowing about these machines, it is essential to know the working of a closed type TBM. A closed type system consists of a horizontal thick steel cylinder which is known as shield. The shield protects machinery and technicians against the earth above. A cutter head where cutting tools are placed will be on one end of shield towards tunnel face. Cutter head is heavyset part of TBM. Cutting disks and scrappers are placed in the cutter head. Design of cutter head is mainly based on type of earth to be excavated by the machine. A machine to work in soil will not have cutter disks but only scrappers. A machine to work in rocky strata will have cutter disks mounted in cutter head. There will be suitable number of drive motors for rotating the cutter head. There will be a segment erector which is used to place the tunnel lining segments. There are suitable number of thrust jacks which are responsible for pushing the machine ahead. Tunnel lining can be of concrete or steel; concrete being widely used.

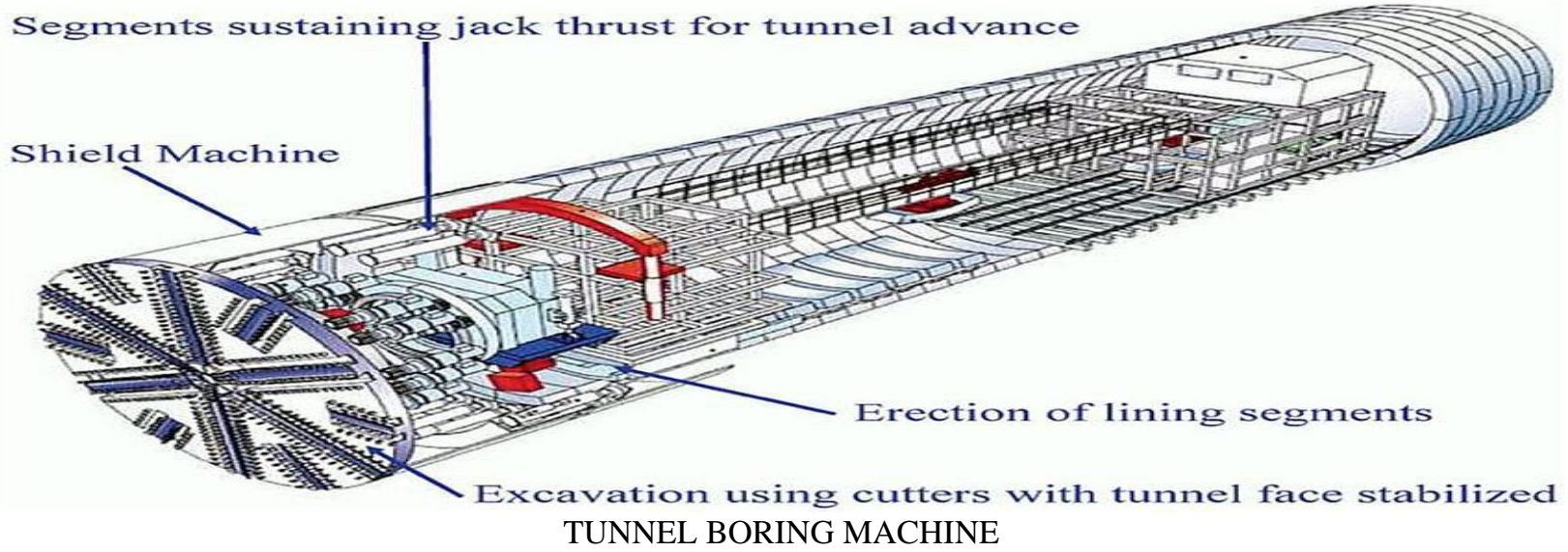




\section{TOPOGRAPHIC MAP}

A topographic map showing alignment of the tunnel and location of all possible arrangements of structures including inlet or intake, control or access shafts, air vents, adits and outlet portal; normally this should be on a scale of 1 inch equals 400 feet (a scale of 1 inch equals 200 feet is preferable for short tunnels) and a contour interval of 5 feet. If a topographic map is unavailable, strip topography may be furnished. Topographic maps of portal sites should be on a scale of 1 inch equals 50 feet and a contour interval of 2 feet and should have contours high enough to include top of portal cut slopes. For flat or gently sloping topography, contour intervals as small as 1 foot may be desirable. Show the coordinate system and existing land survey monuments and special control points established for the topographic survey. Show all manmade features in the included area.

The Building to be surveyed is identified using the topographic map within the range of $50 \mathrm{~m}$ from the tunnel. The impact of vibration during tunnel construction is carried for certain distance the structures which are all comes in that range must be surveyed for precautionary activities.

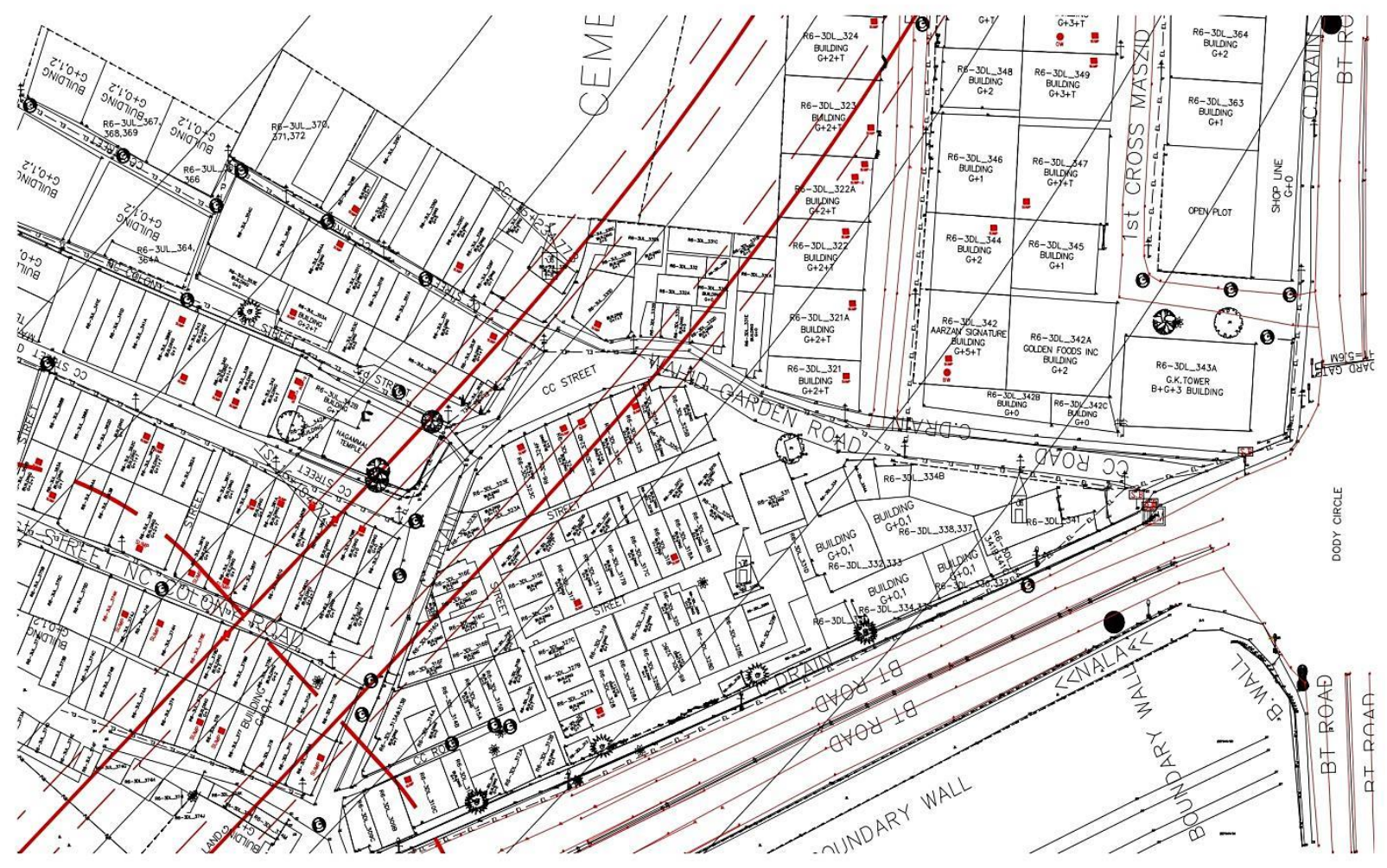

\section{TOPOGRAPHIC MAP OF BANGALORE METRO CONSTRUCTION}

\section{BUILDING CONDITION SURVEY}

A condition survey is a detailed inspection of a building in order to establish its maintenance and repair condition at that time. It is done at a level that surveys each building element, describing it and providing detail of its current state. A condition survey not only provides information for maintenance work that is required immediately - all buildings require maintenance to their fabric over time. This survey also gives an indication of when future repairs, maintenance, decoration and renewal of each part of the building should be anticipated. A condition survey gives visibility of future maintenance commitments that are likely.

\section{Sequence of inspection}

Authorities differ upon the question of whether it is better to commence the full inspection internally or externally. Many suggest that it is better to inspect internally initially as this will cause the least inconvenience to the occupier (Melville et al, 1992), while others seem to suggest that commencing with an external inspection follows more logically the order in which it is usual to report (Hollis, 2000). The writer favours the latter approach as he is not particularly concerned with the sensibilities of the occupier and if anything is missed during the initial inspection of the exterior it is an easy task to re inspect part of the 
exterior again. It may not be as easy to re-inspect the interior again if any problem is suggested by the external inspection. Say, for example, the inspection of the roof-space reveals rain penetration around a chimney stack. If no defect had been identified during the initial external inspection of the stack, it is an easy matter to re-inspect the chimney stack flashings for any sign of a problem. However, let us now assume that the inspection had been carried out in the reverse order and that no defect had been noticed in the roof-space. If then a problem with the flashing is identified by the external inspection it may be more difficult to gain access to the roof space for the second time (perhaps involving unscrewing a trap door, placing dust sheets and erecting a ladder). In many respects the order of inspection is a matter of the personal preference of the surveyor but what is most important is that the inspection is carried out in a logical sequence with which the surveyor is familiar and that the survey or is not afraid to retrace his footsteps in order to follow a trail of evidence.

To summarize the discussion above, the writer's preferred sequence for the inspection of the property is as follows:

- Measured survey of the plot and footprint of the building;

- Inspection of the exterior;

- Inspection of the interior.

\section{Inspecting the exterior}

It is best to inspect each element of construction in turn as this mirrors how the report will be structured. However this is not always practical particularly where the property being inspected is in the centre of a terrace. In such a situation it is necessary to inspect each elevation in turn and indeed this is the method of recording information followed by many surveyors, even when inspecting detached or semi-detached structures. Again such choices are largely a matter of personal preference but whichever method is adopted it is usually best to follow the principle of starting at the top and working down. Thus the following sequence of inspection is recommended:

- Chimney stacks, flashings, cement fillets;

- Roofs, pitched and flat; main slopes, abutments, ridges, hips, verges, ventilation;

- Rainwater goods, gutters, downpipes, gulley or shoe;

- External walls, pointing, movement joints, damp-proof course, sub-floor ventilation;

- External joinery, fascias, soffits, windows, doors;

- Drainage, foul, above ground, below ground, surface water;

- Site, boundaries;

What to actually record during the inspection is not considered in detail in this paper. However there is now available comprehensive advice on this aspect of the inspection. SAVA (2000) have published detailed advice on precisely what to inspect when undertaking the intermediate type of survey (such as a Homebuyers Survey) and are shortly to publish a similar document for building surveys. It is to these documents that a court of law will refer in future should there be any suspicion of professional negligence by the surveyor. If the building being surveyed is large it is likely that the inspection of the exterior will have taken at least one or two hours. Once this is complete it is time to retreat to the interior where the higher temperature and a welcoming cup of coffee will be much appreciated, particularly during the winter months

\section{Inspecting the interior}

The dangers of believing any information volunteered by the vendor are fairly obvious but there will no doubt be some matters that the surveyor wishes to clarify over a reviving beverage (of course an unoccupied and unheated building can be colder than the exterior and in such situations the surveyor will have come prepared with a thermos flask). However once the essential information has been requested of the occupier it is time to gain one's freedom once again and a useful ploy to achieve this is to commence the inspection of the interior in the roof-space. There are not too many vendors who will follow the surveyor into the furthest corners of the roof-space although unfortunately there will always be one or two, including in the writer's experience a very sprightly spinster in her seventies who would not let the surveyor out of her sight! There are however other, perhaps more compelling, reasons for starting in the roof-space. The first of these is that it continues the logical sequence of starting at the top and working down. Another is that it is possible to discover more about the quality of construction in the roof-space, where the builder would have made no attempt to disguise any short-comings, than anywhere else in a building. It is very often possible to date a building more precisely from within the roof-space. Even if the builder erected no plaque on the elevations to date the building, his tradesmen often left evidence in the form of an engraving in a roof-timber or cement rendering to a chimney breast (or even on some rare occasions a discarded newspaper read during their lunch-break). Finally a relatively high number of defects or matters requiring improvement are often identified in the roof-space. This is an area of their dwelling into which many owners or occupiers never venture and they are very often not aware of some of the defects revealed by a survey. The essential matters which need to be investigated during a roof-space inspection are: 
- Structural integrity of the frame;

- Evidence of fungal decay and insect infestation to timber members;

- Condition of the underside of roof coverings, or where felted or boarded, the felt or boarding;

- Condition of gable and party walls where applicable;

- Condition of chimney breasts and flues, including support provided where where removed at lower levels;

- Type and condition of ceilings;

- Presence of, extent of and condition of insulation;

- Condition of water tanks and plumbing;

- Type, age and condition of electrical wiring;

- Evidence of rodent, bird, bat and wasp infestation;

- Adequate ventilation. Once the roof-space has been inspected each room (including circulation areas such as landings and staircases) should be inspected in detail. Again a logical sequence should be followed, such as inspecting in turn:

- Ceiling;

- Each wall (usually four);

-Window(s);

- Door(s);

- Radiator/heater/fireplace;

- Electrical fittings;

- Floor.

Again it will be seen that the philosophy of working downwards from the top has been followed in each room and it is likely that the upper floors would be inspected before the ground floor (and basement if there is one). The surveyor will already be located at upper floor level after inspecting the roof space and with any luck the owner or occupier will not be encountered again until the ground floor is reached.

\section{What should be recorded?}

Since the surveyor will need to convert his notes into the report it is important that the notes taken reflect what will be required in the report. For each element of construction it is necessary to record the following :

1. design and construction;

2. condition;

3. cause of any defects (or recommend further investigation);

4. remedial work required.

\section{How should the information be recorded?}

There are a variety of methods of recording information on site and each surveyor will develop a preference for the method they employ. Each method is considered below:

- Taking notes by long-hand. This is obviously the most time consuming method but there should be a clear record of the inspection to rely upon at a later date, should that be necessary. 
- Dictating notes into a portable tape-recorder for transcription back in the office. Provided there are no recording problems this is less time consuming on site (most people can talk seven times faster than they can write). However there is the delay while the notes are typed up and before the report can be commenced. There is also the disadvantage of having to dictate out of hearing of the owner or occupier.

- Both of the above methods can be supplemented by the use of site prepared sketches and many surveyors prefer to make their notes of each elevation on a sketch of that elevation. This approach has been strongly advocated by one leading authority (Hollis, 1995).

- Notes can be written on a pre-printed form or checklist. This method saves time in that the surveyor does not need to write most of the headings but it can be rather cumbersome. However the checklist approach is probably the best method for inexperienced surveyors.

- Dictating the report directly on site either for word-processing by a secretary or for use directly into speech recognition software - many practices have adopted the latter approach recently. There is no doubt that this is the quickest method and that adopted by many experienced surveyors who do not like to return to the office until after the report is substantially dictated. However in the case of Watts $\mathrm{v}$ Morrow (1991) the Judge considered that this method did not provide the surveyor the opportunity for reflective thought, which is most important when considering the property as a whole. The absence of any site notes leads the surveyor open to a claim of negligence when adopting this method. The writer suspects that those adopting this approach feel that commercial pressures outweigh the risks of being sued for negligence. No doubt a Judge would look more favourably upon a surveyor adopting this approach if there were some sketches with at least a minimum of annotation to record the inspection.

- Entering data directly into a hand held computer. This method is only suitable for stock condition surveys and not when any large volumes of text need to be included.

\section{Summary}

When carrying out domestic condition surveys an initial mechanistic task such as sketching the site and roof plans is recommended in order for the surveyor to achieve focus, familiarity and freedom to inspect alone. The writer recommends that the inspection commence with the exterior, followed by the interior, and that in general a top down approach be adopted. Note taking for each element should record design and construction, condition, cause of defects and then finally any remedial work required. Whichever method of note taking is used, the most important principle to observe is that there should be a comprehensive record of the inspection, to which to refer, if necessary, at a later date.

\section{SITE EXPLORE}

The structure we visited is located at Bangalore. The company named Skytree Consulting Engineers who is the subcontractor for L\&T working for Bangalore Metro Rail Corporation (BMRCL). The work is to provide reports for the buildings which are comes under the range of the tunnel to avoid damage due to tunneling process.

- The photographs of significant defects in the building are taken

- Based on our initial findings we did not perform any analysis of existing structural elements

- Document our findings with qualitative recommendation for remedial work, if required.

- Prepare a report summarizing our findings and giving the suitable damage category of the building.

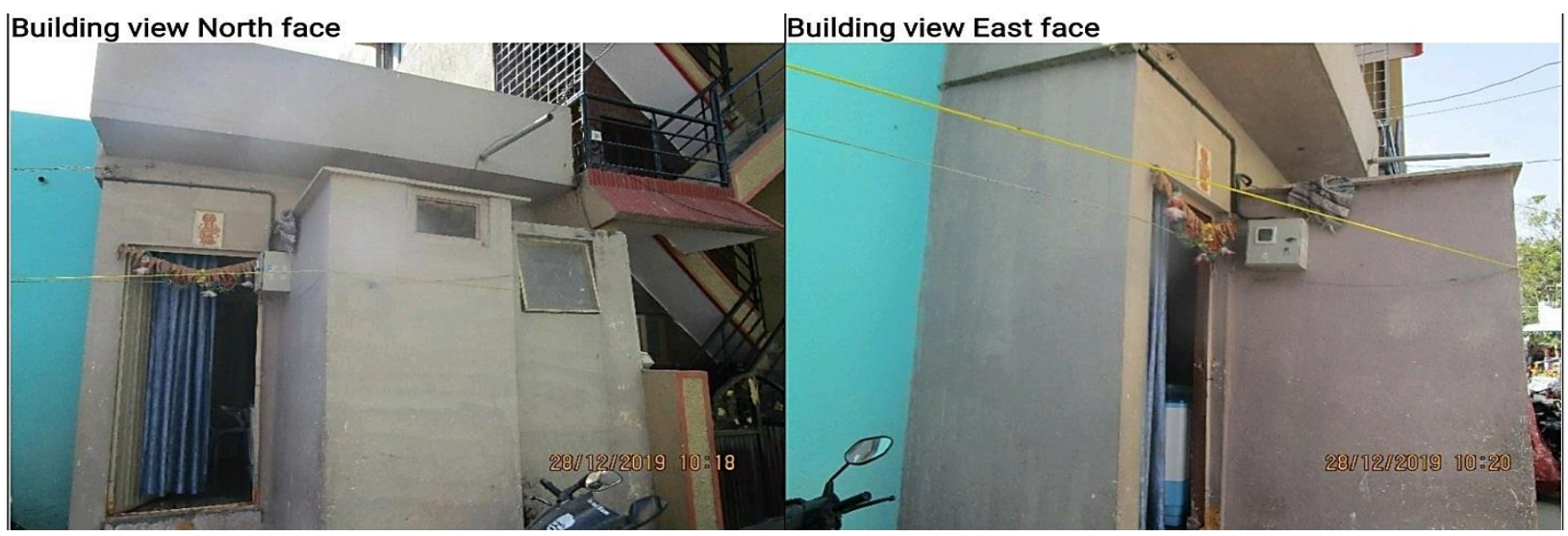



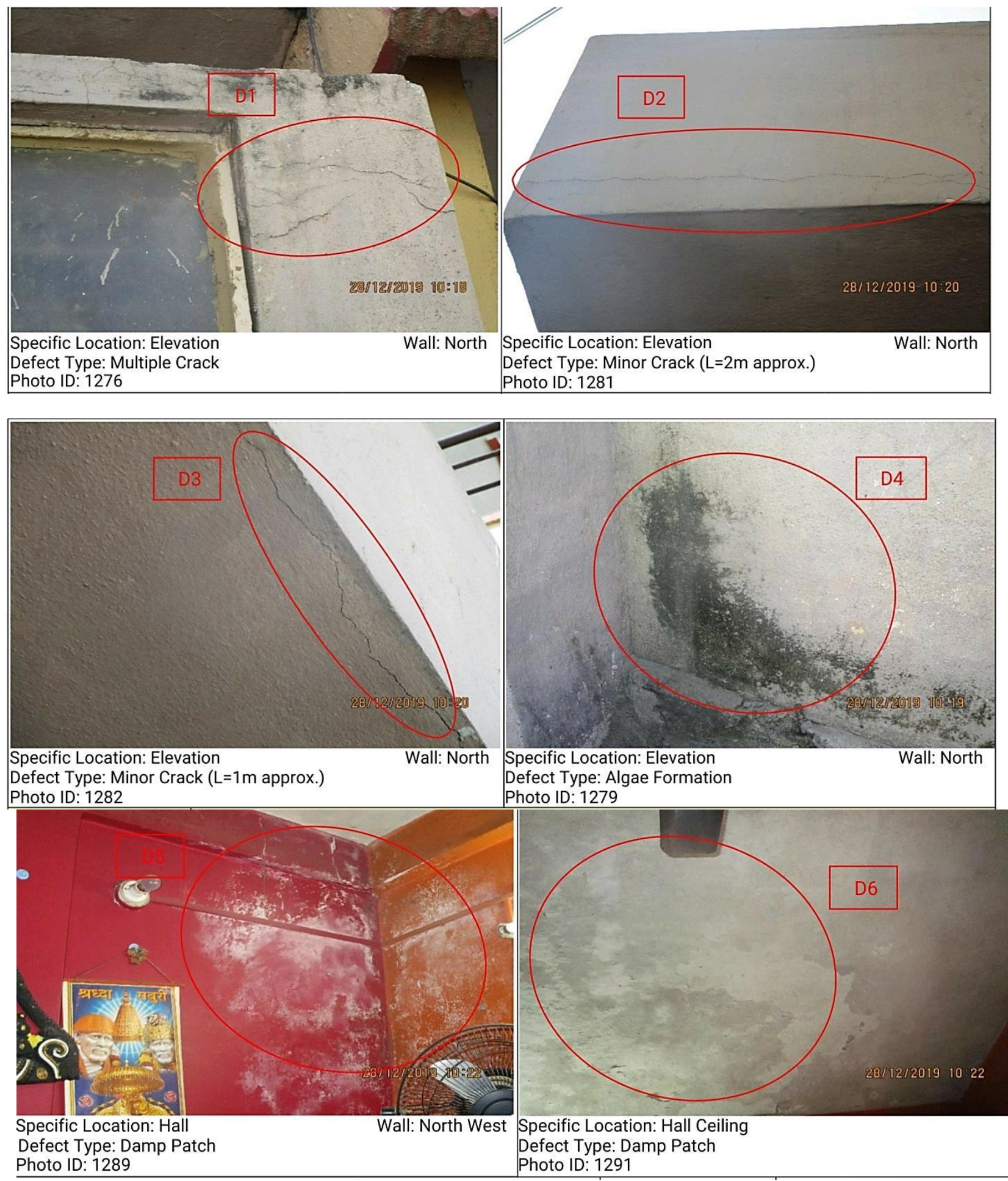


\section{STRUCTURAL ASSESMENT REPORT}

\section{A. Classification ofDefects/Damages}

\begin{tabular}{|c|c|c|}
\hline Degree of damage & $\begin{array}{l}\text { Description of typical damage and likely form of repair for } \\
\text { typical masonry buildings }\end{array}$ & $\begin{array}{l}\text { Number of } \\
\text { Occurrences }\end{array}$ \\
\hline Negligible & Non-structural Hairline cracks \& General View & 15 \\
\hline Minor cracks & Non-structural cracks up to approximate $3 \mathrm{~mm}$ wide & 3 \\
\hline Moderate cracks & Non-structural cracks between $3 \mathrm{~mm}$ to $6 \mathrm{~mm}$ wide(approximate) & - \\
\hline \multirow{3}{*}{ Severe cracks } & \multicolumn{2}{|l|}{ More than $6 \mathrm{~mm}$ wide (approximate) Cracks due to: } \\
\hline & - Corrosion ofreinforcement & - \\
\hline & - Through cracks in load bearing walls, beams andcolumns. & - \\
\hline Minor spalled concrete & Spalling up to 0. 1sq.m and sporadic. & - \\
\hline Major spalled concrete & Spalling greater than 0. 1sq.m and extensive. & - \\
\hline Bulging & Defect which is likely to lead to spalling. & - \\
\hline Peeling of Plaster & Plaster peeled off on structural or non-structural members & - \\
\hline Joint Separation & Separation of Wall and structural members or Doors \& windows & 1 \\
\hline Water stain & $\begin{array}{l}\text { Stain on surface indicating ingress of water in past. The surface } \\
\text { is dry during inspection. }\end{array}$ & - \\
\hline Damp patch & Moisture saturated surface with no significant trace of water. & 3 \\
\hline Water seepage & The surface is wet indicating ingress of water. & - \\
\hline Water leakage & Water oozing out from surface. & - \\
\hline Verticality and deflections & A visual assessment of verticality and deflections of the building & - \\
\hline
\end{tabular}

According to Building damage classification (after Burland et al, 1977 and Boscardin and Cording, 1989) the damage category for any building is identified 


\section{Building Damage Classification1 \\ (after Burland et al, 1977 and Boscardin and Cording,} 1989)

\begin{tabular}{|c|c|c|c|c|}
\hline $\begin{array}{c}1 \\
\text { Risk } \\
\text { Categor } \\
\text { y }\end{array}$ & $\begin{array}{l}2 \\
\text { Description } \\
\text { of Degree } \\
\text { of Damage }\end{array}$ & $\begin{array}{l}3 \\
\text { Description of Typical Damage } \\
\text { and Likely Form of Repair for } \\
\text { Typical Masonry Buildings }\end{array}$ & $\begin{array}{c}4 \\
\text { Approx. } \\
\text { Crack } \\
\text { Width(mm } \\
\text { ) } \\
\end{array}$ & $\begin{array}{c}5 \\
\text { Max } \\
\text { Tensile } \\
\text { Strain } \\
\% \\
\end{array}$ \\
\hline 0 & Negligible & Hairline cracks. & & $\begin{array}{l}\text { Less } \\
\text { than } \\
0.05\end{array}$ \\
\hline 1 & Very Slight & $\begin{array}{l}\text { Fine cracks easily treated during } \\
\text { normal redecorations. Perhaps } \\
\text { isolated slight fracture in building. } \\
\text { Cracks in exterior } \\
\text { brickwork visible upon close inspection. }\end{array}$ & 0.1 to 1 & $\begin{array}{c}0.05 \text { to } \\
0.075\end{array}$ \\
\hline 2 & Slight & $\begin{array}{l}\text { Cracks easily filled. Redecoration } \\
\text { probably required. Several slight } \\
\text { fractures inside building. Exterior } \\
\text { cracks visible: some repointing may } \\
\text { be required for weather tightness. } \\
\text { Doors and windows may stick } \\
\text { slightly. } \\
\end{array}$ & 1 to 5 & 0.075 to 0.15 \\
\hline 3 & Moderate & $\begin{array}{l}\text { Cracks may require cutting out and } \\
\text { patching. Recurrent cracks can be } \\
\text { masked by suitable linings. Tack- } \\
\text { pointing and possibly replacement of a } \\
\text { small amountof exterior brickwork } \\
\text { may be required.Doors and windows } \\
\text { sticking. Utility services may be } \\
\text { interrupted. Water tightnessoften } \\
\text { impaired. }\end{array}$ & $\begin{array}{l}5 \text { to } 15 \text { or a } \\
\text { number of } \\
\text { cracks } \\
\text { greater than } \\
3\end{array}$ & 0.15 to 0.3 \\
\hline 4 & Severe & $\begin{array}{l}\text { Extensive repair involving removal } \\
\text { and replacement of sections of } \\
\text { walls, especially over doors and } \\
\text { windows required. Windows and } \\
\text { door frames distorted. Floor slopes } \\
\text { noticeably. Walls lean or bulge } \\
\text { noticeably, some loss of } \\
\text { bearing in beams. Utility } \\
\text { services disrupted. }\end{array}$ & $\begin{array}{l}15 \text { to } 25 \\
\text { but also } \\
\text { depends on } \\
\text { number of } \\
\text { cracks }\end{array}$ & $\begin{array}{l}\text { Greater } \\
\text { than } \\
0.3\end{array}$ \\
\hline 5 & $\begin{array}{l}\text { Very } \\
\text { Severe }\end{array}$ & $\begin{array}{l}\text { Major repair required involving partial or } \\
\text { complete reconstruction. Beams lose } \\
\text { bearing, walls lean badly and require } \\
\text { shoring. Windows broken by distortion. } \\
\text { Danger of instability. }\end{array}$ & $\begin{array}{l}\text { Usually } \\
\text { greater than } \\
25 \text { but } \\
\text { depends on } \\
\text { number of } \\
\text { cracks }\end{array}$ & \\
\hline
\end{tabular}

\section{CONCLUSION}

This survey comprises a detailed survey of the building followed by a comprehensive report. It includes a detailed list of defects, both minor and major, requiring attention, and recommended improvements. The report provides you with a reference on the condition of the building and can form the basis of a record of the condition of the building which can be of great assistance to make precautionary activities to avoid further damage of the building. For the buildings which comes under severe and very severe damage category the buildings must be demolished before tunneling process to avoid collapse and major accidents.

[1] BMRCL Technical Reports (internal), 2010-2016.

\section{REFERENCES}

[2] Melville, I., Gordon, I., and Murrells, P., 1992, Structural Surveys of Dwelling Houses, Estates Gazette, London.

[3] Hollis, M., 2000, Surveying Buildings, RICS Books, Coventry.

[4] Hollis, M., 1995, Property Services - Part 2: The Exterior, The Chartered Surveyors' Education Channel Video.

[5] SAVA, 2000, Benchmark Standards for the Homebuyer Survey and Valuation, Surveyors and Valuers Accreditation, Woking Surrey. 
[6] Watts v Morrow (1991) 4 All ER 937, CA.

[7] Burland et al, 1977 and Boscardin and Cording, 1989

[8] Alani, A. M.; Petersen, A. K.; Chapman, K. G. (2001). Applications of The Developed Quantitative Model In Building Repair and Maintenance Case Study. Facilities. 19(5/6):215-221.

[9] Hoxley, M. (2002). Condition Inspections of Residential Property: A Procedural Framework. Structural Survey. 20(1):31-35.

[10] Kerns, J.A. (2009). What is a Condition Survey. Mid Atlantic Real Estate Journal. Retrieved on 15th March 2010,

[11] Lee, R. (1987). Building Maintenance Management. 3rd Edition. United Kingdom: William Collins Sons \& Co. Ltd. Reprinted by Blackwell Science.

[12] Pitt, T. J. (1997). Data Requirements for The Prioritization of Predictive Building Maintenance. Facilities. 15(3/4):97-104

[13] Watt, D.S. (1999). Building Pathology: Principles \& Practice. Blackwell Science Ltd.

[14] Rahah, I. (2009). The Property Market Response to the Global Economic Crisis, A paper presented in New Approach in Land Development 2009 Seminar, Retrieved on 9th April 2010,

[15] Mustafa, N.K.F., Roslan, S.N.A., Zakariah, H., Tawil, N.M., Hashim A.E. (2009). Sustainable Building through Refurbishment: A Case Study of The Kuala Lumpur Central Market, Journal of Design + Built, 2:52-61

[16] Che-Ani. A.I. (2008b). Role and Methods of Building Defects Inspection. Building Maintenance Course: Building Inspection Technology \& Performance Monitoring. Building \& Urban Dev. Inst (BUDI).

[17] Che-Ani A.I., Ramly, A., Zain, M.F.M., Tawil, N.M., Hashim, A.E (2008a). "Assessing The Condition of Traditional Khmer Timber Houses In Cambodia - A Priority Ranking Approach". Journal of Building Appraisal. 4(2) Summer 2008:87-102 